\title{
Polar Drift in the 1990s Explained by Terrestrial Water Storage Changes
}

\author{
Deng, S.; Liu, Sihang; Mo, X.; Jiang, Liguang; BauerGottwein, Peter
}

\section{Published in:}

Geophysical Research Letters

Link to article, DOI:

10.1029/2020GL092114

Publication date:

2021

Document Version

Publisher's PDF, also known as Version of record

Link back to DTU Orbit

Citation (APA):

Deng, S., Liu, S., Mo, X., Jiang, L., \& BauerGottwein, P. (2021). Polar Drift in the 1990s Explained by Terrestrial Water Storage Changes. Geophysical Research Letters, 48(7), [e2020GL092114].

https://doi.org/10.1029/2020GL092114

\section{General rights}

Copyright and moral rights for the publications made accessible in the public portal are retained by the authors and/or other copyright owners and it is a condition of accessing publications that users recognise and abide by the legal requirements associated with these rights.

- Users may download and print one copy of any publication from the public portal for the purpose of private study or research.

- You may not further distribute the material or use it for any profit-making activity or commercial gain

- You may freely distribute the URL identifying the publication in the public portal 


\section{Geophysical Research Letters}

\author{
RESEARCH LETTER \\ 10.1029/2020GL092114 \\ Key Points: \\ - Past climate-driven polar motion \\ was quantified by modeling \\ terrestrial water storage under two \\ different scenarios \\ - One scenario was based on GRACE \\ and reanalysis data; another scenario \\ was based on extra glacier change \\ observations \\ - Rapid terrestrial water storage \\ decline caused by ice melting over \\ glacial areas drove the polar drift \\ toward the east in the 1990s
}

Supporting Information:

Supporting Information may be found in the online version of this article.

Correspondence to:

S. Liu,

liusx@igsnrr.ac.cn

Citation:

Deng, S., Liu, S., Mo, X., Jiang, L., \& Bauer-Gottwein, P. (2021). Polar drift in the 1990s explained by terrestrial water storage changes. Geophysical Research Letters, 48, e2020GL092114. https://doi. org/10.1029/2020GL092114

Received 16 DEC 2020 Accepted 16 MAR 2021

(C) 2021. American Geophysical Union. All Rights Reserved.

\section{Polar Drift in the 1990s Explained by Terrestrial Water Storage Changes}

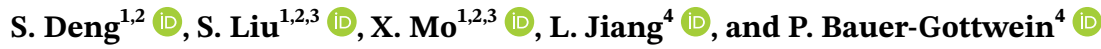 \\ ${ }^{1}$ Key Laboratory of Water Cycle and Related Land Surface Processes, Institute of Geographic Sciences and Natural \\ Resources Research (IGSNRR), Chinese Academy of Sciences (CAS), Beijing, China, ${ }^{2}$ College of Resources and \\ Environment, University of Chinese Academy of Sciences (UCAS), Beijing, China, ${ }^{3}$ Sino-Danish College, University \\ of Chinese Academy of Sciences (UCAS), Beijing, China, ${ }^{4}$ Department of Environmental Engineering, Technical \\ University of Denmark, Kgs Lyngby, Denmark
}

\begin{abstract}
Secular polar drift underwent a directional change in the 1990s, but the underlying mechanism remains unclear. In this study, polar motion observations are compared with geophysical excitations from the atmosphere, oceans, solid Earth, and terrestrial water storage (TWS) during the period of 1981-2020 to determine major drivers. When contributions from the atmosphere, oceans, and solid Earth are removed, the residual dominates the change in the 1990s. The contribution of TWS to the residual is quantified by comparing the hydrological excitations from modeled TWS changes in two different scenarios. One scenario assumes that the TWS change is stationary over the entire study period, and another scenario corrects the stationary result with actual glacier mass change. The accelerated ice melting over major glacial areas drives the polar drift toward $26^{\circ} \mathrm{E}$ for 3.28 mas/yr after the $1990 \mathrm{~s}$. The findings offer a clue for studying past climate-driven polar motion.
\end{abstract}

Plain Language Summary The Earth's pole, the point where the Earth's rotational axis intersects its crust in the Northern Hemisphere, drifted in a new eastward direction in the 1990s, as observed by space geodetic observations. Generally, polar motion is caused by changes in the hydrosphere, atmosphere, oceans, or solid Earth. However, short-term observational records of key information in the hydrosphere (i.e., changes in terrestrial water storage) limit a better understanding of new polar drift in the 1990s. This study introduces a novel approach to quantify the contribution from changes in terrestrial water storage by comparing its drift path under two different scenarios. One scenario assumes that the terrestrial water storage change throughout the entire study period (1981-2020) is similar to that observed recently (2002-2020). The second scenario assumes that it changed from observed glacier ice melting. Only the latter scenario, along with the atmosphere, oceans, and solid Earth, agrees with the polar motion during the period of 1981-2020. The accelerated terrestrial water storage decline resulting from glacial ice melting is thus the main driver of the rapid polar drift toward the east after the 1990s. This new finding indicates that a close relationship existed between polar motion and climate change in the past.

\section{Introduction}

Polar motion, which is the motion of the Earth's rotational axis relative to its crust, has been routinely observed using space geodetic observation techniques for more than a century (Anderle, 1973; Anderle \& Beuglass, 1970). It is described in an Earth-fixed reference frame, where the origin is the Conventional International Origin and the $X$ and $Y$ coordinate axes point toward the $0^{\circ}$ and $90^{\circ} \mathrm{W}$ longitudes, and it is given in units of milliseconds of $\operatorname{arc}$ (mas; 1 mas $\approx 3 \mathrm{~cm}$ ). Compared to its motion range (tens to hundreds of mas), its observed uncertainty, which is much less than 1 mas, is negligible. Several recent studies (Adhikari \& Ivins, 2016; J. L. Chen et al., 2013; Roy \& Peltier, 2011) state that this long-term, high-accuracy record of the Earth's pole provides key information about climate change.

Generally, polar motion is triggered by the mass redistribution and movement of the solid Earth, atmosphere, and hydrosphere on various time scales (Höpfner, 2004). Two dominant periodic oscillations of polar motion, that is, the annual and Chandler wobbles are mostly excited by winds, ocean currents, atmospheric pressure fluctuations, and ocean bottom changes (J. L. Chen et al., 2012; R. S. Gross, 2000; Höpfner, 2004). The low-frequency components of polar motion, especially the linear polar drift over the 20th century, are 
considered to be mostly related to the solid Earth, especially the glacial isostatic adjustment (GIA) process and mantle convection (Adhikari et al., 2018; R. S. Gross \& Vondrák, 1999; McCarthy \& Luzum, 1996; Nakada et al., 2015). Beyond these predictable variations, other irregular components of polar motion, especially interannual and interdecadal movements, are likely climate-related and have attracted extensive research interest. R. Gross and Poutanen (2009) first noticed a directional change in secular polar drift in the mid1990s. Roy and Peltier (2011) further showed that the direction of secular polar drift significantly changed from $68^{\circ} \mathrm{W}$ (1976-1992) to $58^{\circ} \mathrm{W}$ (1992-2008). Surprisingly, this change is not caused by either GIA or the mantle convection. Roy and Peltier (2011) suggested that it might be influenced by accelerated ice melting over glacial areas under global warming. However, a lack of key observations, that is, terrestrial water storage (TWS), brings challenges to further studies. TWS represents all forms of water stored on or below the land surface, including snow, ice, groundwater, soil moisture, surface water, and water stored in the canopy and biomass (Hirschi et al., 2007; Kumar et al., 2016). It reflects the net effect of all hydrological flux variables and is, therefore, a key variable for the water cycle and climate change (Long et al., 2017). In 2002, the launch of the twin Gravity Recovery and Climate Experiment (GRACE) satellites (Tapley et al., 2004) represented a breakthrough in TWS mapping. During the GRACE era, J. L. Chen et al. (2013) showed that the accelerated ice melting over Greenland in approximately 2005 drove eastward pole drifting based on GRACE data. Adhikari and Ivins (2016) further pointed out that TWS also plays an important role in decadal-like polar motion: TWS explains $\sim 83 \%$ of the peak-to-peak amplitude of polar motion during the period of 2003-2015, and a shift in the global wet-dry pattern dominated a westward drift of polar motion in approximately 2012.

Although climate-driven polar motion became clear during the GRACE era, retrieval of reliable climate-related information on polar motion prior to the GRACE era remains a challenge. Unlike better developed solid Earth, atmosphere, and ocean models, producing actual TWS estimates is a major problem. Many approaches have been proposed to reconstruct long-term TWS (Alkama et al., 2010; J. L. Chen \& Wilson, 2005; Hirschi \& Seneviratne, 2017; Hirschi, Seneviratne, \& Schar, 2006; Hirschi, Viterbo, \& Seneviratne, 2006; Mueller et al., 2011; Seneviratne et al., 2004; Tang et al., 2010). Scanlon et al. (2018) reported that TWS trends from hydrological models deviated significantly from the trends obtained from GRACE. Other alternative approaches for estimating TWS are thus valuable in revealing climate-driven polar motion. This study proposes linking the secular polar drift in the 1990s with climate change by testing contributions from simulated TWS under different assumptions. The specific steps include (1) separating the contributions of other excitation sources, that is, the GIA, oceans, and atmosphere, to confirm whether these sources drive secular polar drift in the 1990s; (2) determining the dominant role of TWS in the residual using GRACE and its follow-on mission (GRACE-FO) data; and (3) reconstructing a lengthened TWS based on GRACE/ GRACE-FO and reanalysis data and a corrected TWS based on observed glacial change data to assess whether global TWS changes, especially accelerated ice melting over glacial areas, were most likely responsible for polar drift in the 1990s.

\section{The Directional Change in Secular Polar Drift in the 1990s}

The contribution of multiple excitation sources to polar motion can be quantified by comparing excitations derived from observations and models. Figures $1 \mathrm{a}$ and $1 \mathrm{~b}$ show contributions from the modeled GIA, oceans, and atmosphere to polar motion from January 1981 to June 2020. The geodetic (observed) and geophysical (atmospheric and oceanic) excitations were obtained from the International Earth Rotation and Reference Systems Service (IERS). When manually selecting parameters, the Chandler period of the observed excitation was set as 433 days; the Chandler quality factor was set as 100; the simulation of atmospheric mass redistribution and movement was set based on the European Centre for Medium-Range Weather Forecasts (ECWMF); and the simulation of ocean current and ocean bottom pressure change was set based on the Max Planck Institute Ocean Model (MPIOM). Given that the excitation from the solid Earth is mainly attributed to GIA, this study also takes its effect into account. It is approximately equal to the linear trends of $0.79 \mathrm{mas} / \mathrm{yr}$ for $\chi_{1}$ and $-2.95 \mathrm{mas} / \mathrm{yr}$ for $\chi_{2}$ (Adhikari \& Ivins, 2016). On a time scale that is longer than the annual and Chandler wobbles, the excitation components $\chi_{1}$ and $\chi_{2}$ are approximately equal to the polar motion components $X$ and negative $Y$ (Adhikari \& Ivins, 2016). Therefore, the polar drift in this study is computed by applying a 12- and 14- month moving average to excitations. Its direction and rate are 

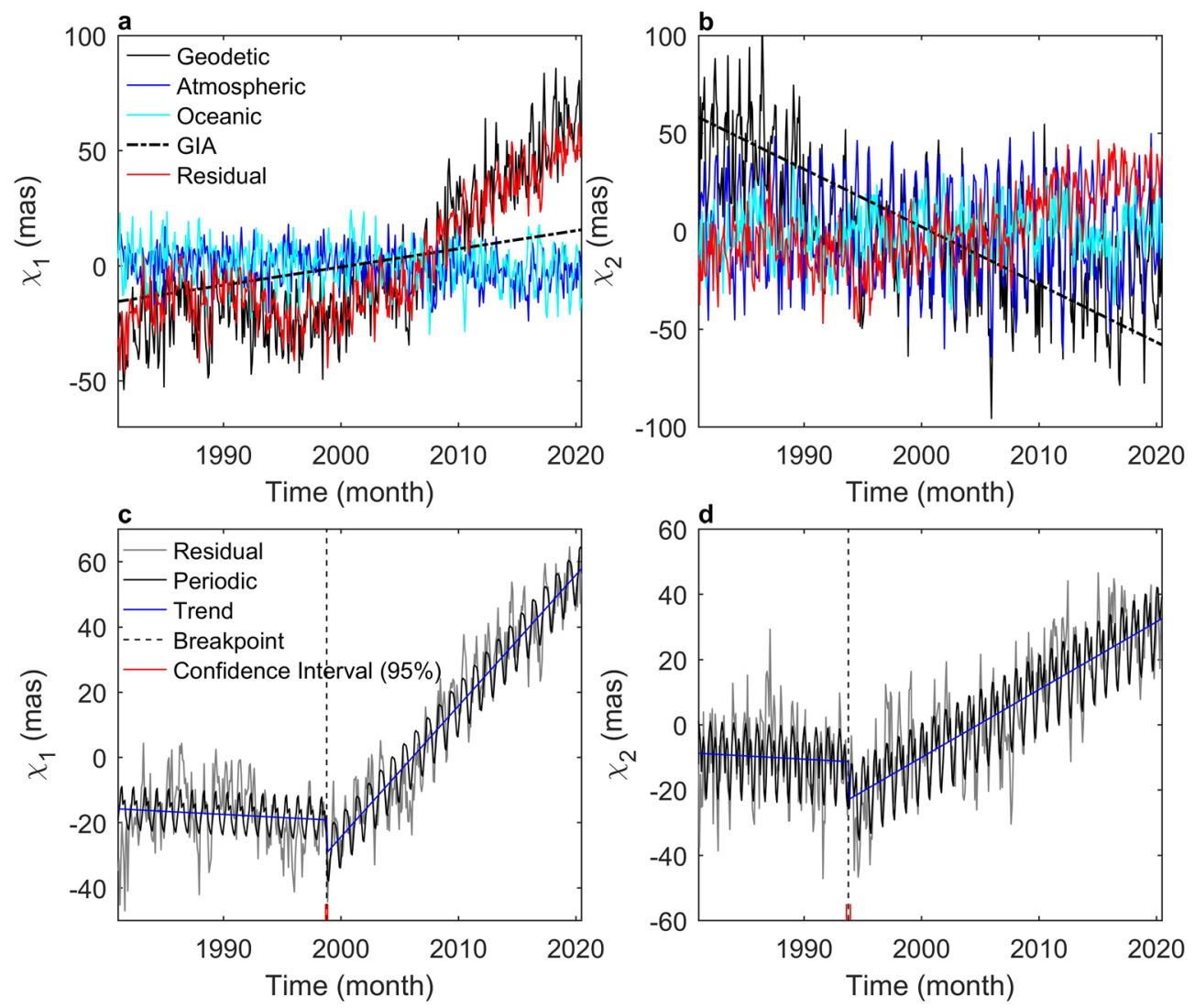

Figure 1. BFAST-detected polar drift in the 1990s from January 1981 to June 2020. (a and b) show the monthly time series of the geodetic excitation, the geophysical excitations, and their residuals for $\chi_{1}$ and $\chi_{2}$, respectively. (c and d) are the breakpoint detection results of the residual using BFAST for $\chi_{1}$ and $\chi_{2}$, respectively. BFAST, Breaks for Additive Season and Trend.

thus the moving direction and rate of the linear fitting line of polar drift on the Earth's surface. Polar motion observations show that the Earth's pole drifted generally toward $\sim 40^{\circ} \mathrm{W}$ at a rate of $\sim 2.95$ mas/yr during January 1981 and June 2020. Among the three sources of polar motion shown in Figure 1, only the GIA significantly drives the secular polar drift, and it accounts for $~ 35 \%$ and $\sim 157 \%$ of the variance contributions for $\chi_{1}$ and $\chi_{2}$, respectively. Adding atmospheric and oceanic contributions only changes the variance contributions by an additional $\sim-14 \%$ and $\sim-5 \%$. The residuals of the oceanic, atmospheric, GIA-related, and observed excitations (more data processing details are provided in Text S1), which explain $\sim 81 \%$ and $\sim-60 \%$ of the variance contributions for $\chi_{1}$ and $\chi_{2}$, are thus crucial for closing the excitation function budget. Since GIA is assumed to change linearly under the influence of the late Quaternary ice age, the directional change in polar drift in the 1990s is expected to remain in the residuals after subtracting oceanic, atmospheric, and GIA-related excitations. The Breaks for Additive Season and Trend algorithm (Verbesselt et al., 2010) is used to detect breakpoints of the residual because it can effectively detect changes in the long-term trend of the time series in the context of strong periodic changes (Watts \& Laffan, 2014). Figures 1c and 1d show that there are breakpoints in $\chi_{1}$ in approximately October 1998 and in $\chi_{2}$ in approximately October 1993 for the residual, which is roughly consistent with the conclusions of R. Gross and Poutanen (2009) (in the mid1990s) and Roy and Peltier (2011) (in approximately 1992). Considering the different results of the two components, the breakpoint of polar drift in the residual is set in October 1995. This study also finds that only for shorter time intervals, for example, 1995-2011, the breakpoints for the two components detected in approximately 2005, similar to the findings of J. L. Chen et al. (2013), which are November 2006 and October 2006 (Figures S2 and S3). The long-term path of observed excitation from 1981 to 2020 further reveals that there is a more significant change in the direction of polar drift that occurred in approximately 1995 (Figure S4). 
In October 1995 , the direction of polar drift in the residual changed from $77^{\circ} \mathrm{W}$ to $28^{\circ} \mathrm{E}$, which is roughly similar to that of the entire observed change, that is, eastward for approximately $71^{\circ}$ (from $85^{\circ} \mathrm{W}$ to $14^{\circ} \mathrm{W}$ ).

\section{Comparison of the Excitations of the Residual and GRACE/GRACE-FO- Derived TWS}

After the contributions by the GIA, atmosphere, and ocean have been removed, most of the changes in polar motion are likely attributed to changes in the hydrosphere (Adhikari \& Ivins, 2016; J. L. Chen et al., 2013; Liu et al., 2018). This study thus further compares the residual and the hydrological excitation at the regional to global scales to help determine the specific drivers of the common directional change in both the secular polar motion and its residual. Limited by insufficient hydrological observations, the comparison is first conducted over the GRACE/GRACE-FO periods. The GRACE/GRACE-FO-derived TWS anomaly data, which are processed (Watkins et al., 2015) at the Jet Propulsion Laboratory (JPL) using the mascon approach (Release 06 Version 02), are employed in this study. These data guarantee that the same atmospheric, oceanic, and GIA simulations used in producing the residual are used to extract TWS from the original GRACE/GRACE-FO data (more data processing details are provided in Text S2). Finally, the GRACE/ GRACE-FO-derived TWS data are further converted to the excitation domain as the hydrological excitation (more details are provided in Text S3) to enable the comparison with the residual.

Figure 2 presents the comparison results for the period of April 2002 to June 2020. The monthly hydrological excitation is highly consistent with the residual; the correlation coefficients are as high as 0.92 and 0.82 , with the peak-to-peak amplitude accounting for $70 \%$ and $66 \%$ for $\chi_{1}$ and $\chi_{2}$, respectively (Figures $2 \mathrm{a}$ and $2 \mathrm{~b}$ ). The TWS-related polar drift, which moves toward $22^{\circ} \mathrm{E}$, is also in good agreement with that of the residual $\left(28^{\circ} \mathrm{E}\right)$ in direction (Figures $2 \mathrm{c}$ and $2 \mathrm{~d}$ ), and the movement rate of the TWS-related polar drift (2.58 mas/yr) accounts for $65 \%$ of that of the residual (3.95 mas/yr). According to the study of Adhikari et al. (2018), the discrepancy in direction $\left(6^{\circ}\right)$ and, in particular, rate (1.37 mas/yr) is reasonable when mantle convection is not considered in this study.

Moreover, there is a pronounced difference in the hydrological excitations between polar regions (Greenland and Antarctic) and nonpolar regions. The hydrological excitation in the polar regions is almost linear in time for both components during the study period (Figures $2 \mathrm{a}$ and $2 \mathrm{~b}$ ). The mean net trends of the hydrological excitation in the polar regions are $2.78 \mathrm{mas} / \mathrm{yr}$ for $\chi_{1}$ but only -0.43 mas/yr for $\chi_{2}$. The TWS change in polar regions has driven the pole toward $9^{\circ} \mathrm{W}$ for approximately 45 mas in 219 months, which mostly explains the moving distance of TWS-related polar drift toward $\chi_{1}$ (Figures $2 \mathrm{c}$ and $2 \mathrm{~d}$ ). In contrast, the hydrological excitation in the nonpolar regions has stronger periodic changes for both components and has driven the pole toward $83^{\circ} \mathrm{E}$ for approximately 31 mas in 219 months. TWS changes in nonpolar regions mostly excited the residual toward $\chi_{2}$ in terms of both the drift direction and peak-to-peak amplitude (73\%) (Figures 2b and 2d). Previous studies (Adhikari \& Ivins, 2016; J. L. Chen et al., 2013) have also found that the TWS in nonpolar regions explains the residual excitation better for $\chi_{2}$ than for $\chi_{1}$, and the preliminary explanation is that global lands are mostly distributed along the $\chi_{2}$ direction. Here, we quantify the contributions from polar regions to $\chi_{1}$ and from nonpolar regions to $\chi_{2}$. Considering that the directional change occurred in both components, it is reasonable to infer that TWS probably underwent a significant change in both the polar regions and the nonpolar regions, for example, rapid ice melting or a wet-dry pattern shift across the continents, in the 1990s.

\section{Causes of Polar Drift in the 1990s: Accelerated Ice Melting}

This section investigates whether TWS underwent a global change and caused a change in polar drift in the 1990s. First, this study assumes that the spatiotemporal characteristics, for example, the rates of ice melting and groundwater depletion, of GRACE/GRACE-FO-derived TWS change are stationary throughout the entire period of 1981-2020. Then, this assumption is tested by explaining the residual.

The assumption is made by lengthening GRACE/GRACE-FO-derived TWS using an improved empirical orthogonal function (EOF) (Yu et al., 2018) analysis. This analysis method decomposes the GRACE/GRACEFO-derived TWS into several fixed spatial modes and corresponding time series. Given that spatial modes 

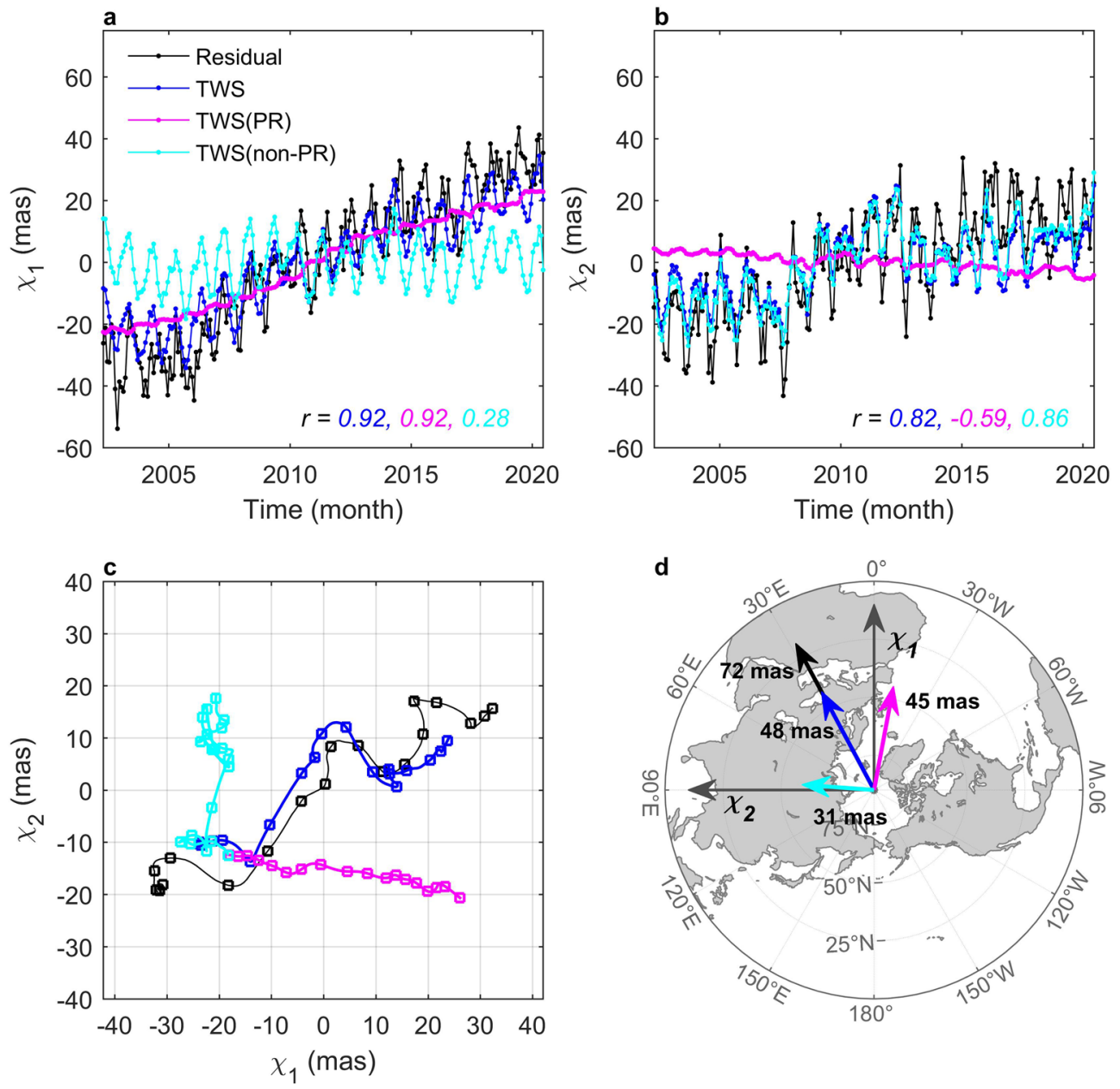

Figure 2. Comparison between the residual and GRACE/GRACE-FO-derived hydrological excitations for (a) $\chi_{1}$, (b) $\chi_{2}$, and (c) the polar drift path from April 2002 to June 2020. (d) Multiple sources drove polar drifts from April 2002 to June 2020 (219 months) on the Earth's surface. PR indicates the polar regions. GRACE, Gravity Recovery and Climate Experiment; GRACE-FO, GRACE and its follow-on mission.

are stationary in time under this assumption, lengthening only requires extending the corresponding time series. An initial TWS estimate throughout the entire study period of 1981-2020, which is the summation of the snow and soil water from ERA5-Land reanalysis, is introduced to help extend the time series. By applying the EOF analysis to this initial TWS estimate, an initial longer-term time series is obtained. The extended GRACE/GRACE-FO-related time series are then computed by correcting this initial longer time series based on the linear relation between time series derived from GRACE/GRACE-FO and ERA5-Land. By multiplying the fixed spatial modes of GRACE/GRACE-FO by the extended GRACE/GRACE-FO-related time series, the lengthened TWS is obtained. More details about lengthening are provided in Text S4. It exhibits the same seasonal fluctuation patterns and linear trends as the GRACE/GRACE-FO-derived pattern at a regional to global scale (Figure S5).

The lengthened TWS is converted into the excitation domain to explain the residual. The hydrological excitation based on the lengthened TWS is similar to the residual between October 1998/1993 and June 2020 (Figure 3). Their correlation coefficients are 0.93 and 0.84 with peak-to-peak amplitudes accounting for $78 \%$ and $58 \%$ for $\chi_{1}$ and $\chi_{2}$, respectively. The consistency with the residual of the lengthened TWS from the 1990s to 2020 is comparable to that of the GRACE/GRACE-FO era, which reveals a high accuracy. Moreover, from the 1990s to present, the lengthened TWS is also significantly correlated with the water level observed by satellite altimetry in four giant lakes (East Aral Sea, West Aral Sea, Lake Ontario and Lake Ladoga) (Figure S6). The surface areas of these lakes are at least larger than one grid cell $\left(\sim 12,321 \mathrm{~km}^{2}\right)$ of TWS data to 

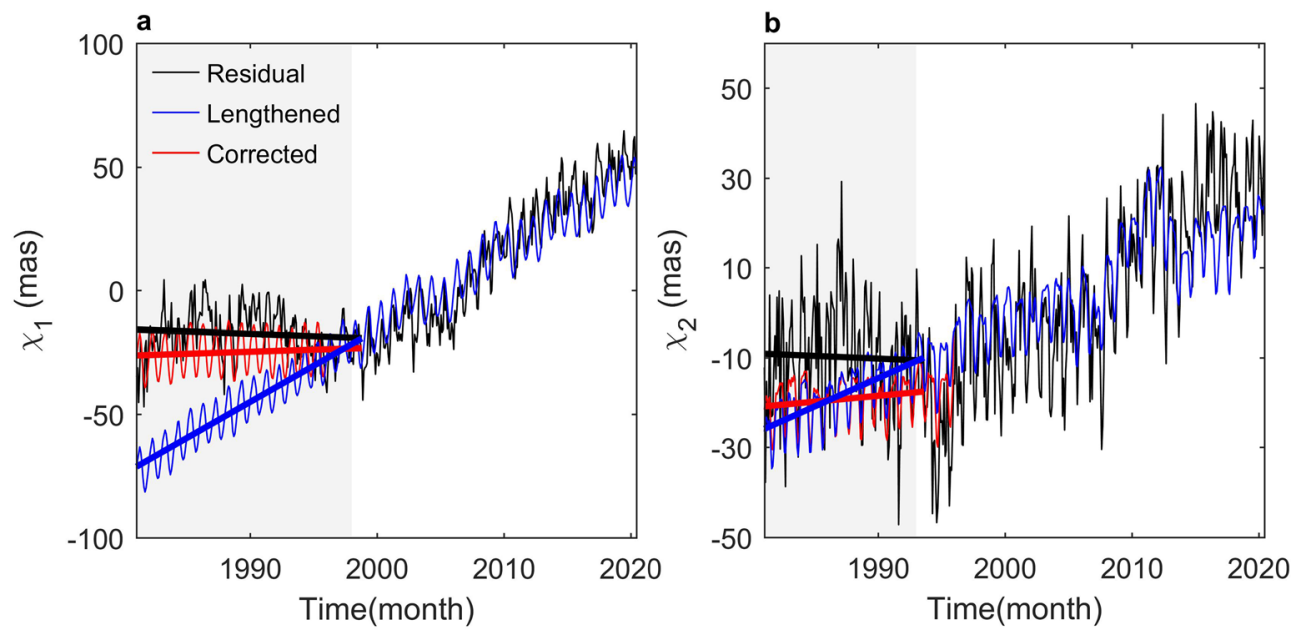

Figure 3. The comparison between the residual and hydrological excitations based on the lengthened GRACE/ GRACE-FO TWS before and after correction for (a) $\chi_{1}$ and (b) $\chi_{2}$. GRACE, Gravity Recovery and Climate Experiment; GRACE-FO, GRACE and its follow-on mission; TWS, terrestrial water storage.

guarantee that TWS is mainly affected by lakes in these grids. However, the lengthened TWS cannot explain the residual before the 1990s. The linear trend of the residual before October 1998 (and 1993) is -0.19 mas/ $\mathrm{yr}$ (and $-0.12 \mathrm{mas} / \mathrm{yr}$ ) for $\chi_{1}$ (and $\chi_{2}$ ), when that of the hydrological excitation based on the lengthened TWS is 2.93 (and 1.26). Beyond the difference in the linear trend, the peak-to-peak amplitude after trend removal is also significant. Before October 1998 (and 1993), hydrological excitation based on the lengthened TWS only accounts for $46 \%$ (and 23\%) of the peak-to-peak amplitude of $\chi_{1}$ (and $\chi_{2}$ ), which decreased by $22 \%$ (and 34\%) compared with that after October 1998 (and 1993). The accuracy of the lengthened TWS is challenged between 1981 and the 1990s: that is, the assumption of the TWS lengthening is challenged during this period. The EOF decomposition of GRACE/GRACE-FO is not stationary in time and the spatiotemporal characteristics of the actual TWS probably changed in the 1990s.

To identify specific regions that underwent a significant change and drove polar drift in the 1990s, Figure 4 shows the impacts of the regional TWS change on polar motion during the GRACE/GRACE-FO era. Several areas, for example, Alaska, Greenland, the Southern Andes, Antarctica, the Caucasus, the Middle East, India, and the North China Plain, mainly contributed to the residual during this period. These areas are recent hotspots of TWS change, for example, glacial melting and groundwater depletion. Most areas, such as Alaska, Greenland, the Southern Andes, Antarctica, the Caucasus, and the Middle East, have recently exhibited significant glacier mass changes. According to Zemp et al. (2019), Alaska, Greenland, and the Southern Andes are the world's top three areas of glacier mass loss. Figure 4 also shows that the glacier mass change corresponds to the TWS change after the 1990s. The difference in magnitude can be reasonably explained by the difference in data sources and cover ranges (Text S5 and Table S1). For example, the glacier data cover only $\sim 1 \times 10^{5} \mathrm{~km}^{2}$ for Greenland, while the TWS data cover $\sim 1 \times 10^{6} \mathrm{~km}^{2}$, which causes the spatial mean glacier mass change to be one order of magnitude greater than that of TWS. In addition, the observational coverage of glacier mass change data only ranges from $1 \%$ to $79 \%$ of the total glacial area per region. Therefore, the TWS trend of these areas probably mainly attributed to glacier mass change. A previous study (Thomas et al., 2006) suggested that the ice loss in Greenland accelerated sharply after the mid-1990s. According to observed glacier mass change data, the other areas, that is, Alaska, the Southern Andes, Antarctica, the Caucasus, and the Middle East, also experienced sharply accelerated glacier retreats in the 1990s (Figure 4). The lengthened TWS thus cannot capture this rate of change in the 1990s because our hypothesis overestimates the ice melting rates of these areas before the 1990s.

This study attempts to correct the lengthened TWS from January 1981 to December 1995 based on the observed glacier mass change data from Zemp et al. (2019). First, a specific gain factor is computed using the linear regression method for each major glacier area from 1995 to 2018. The input explanatory variable is the yearly observed glacier mass change data, and the input dependent variable is the yearly TWS averaged 

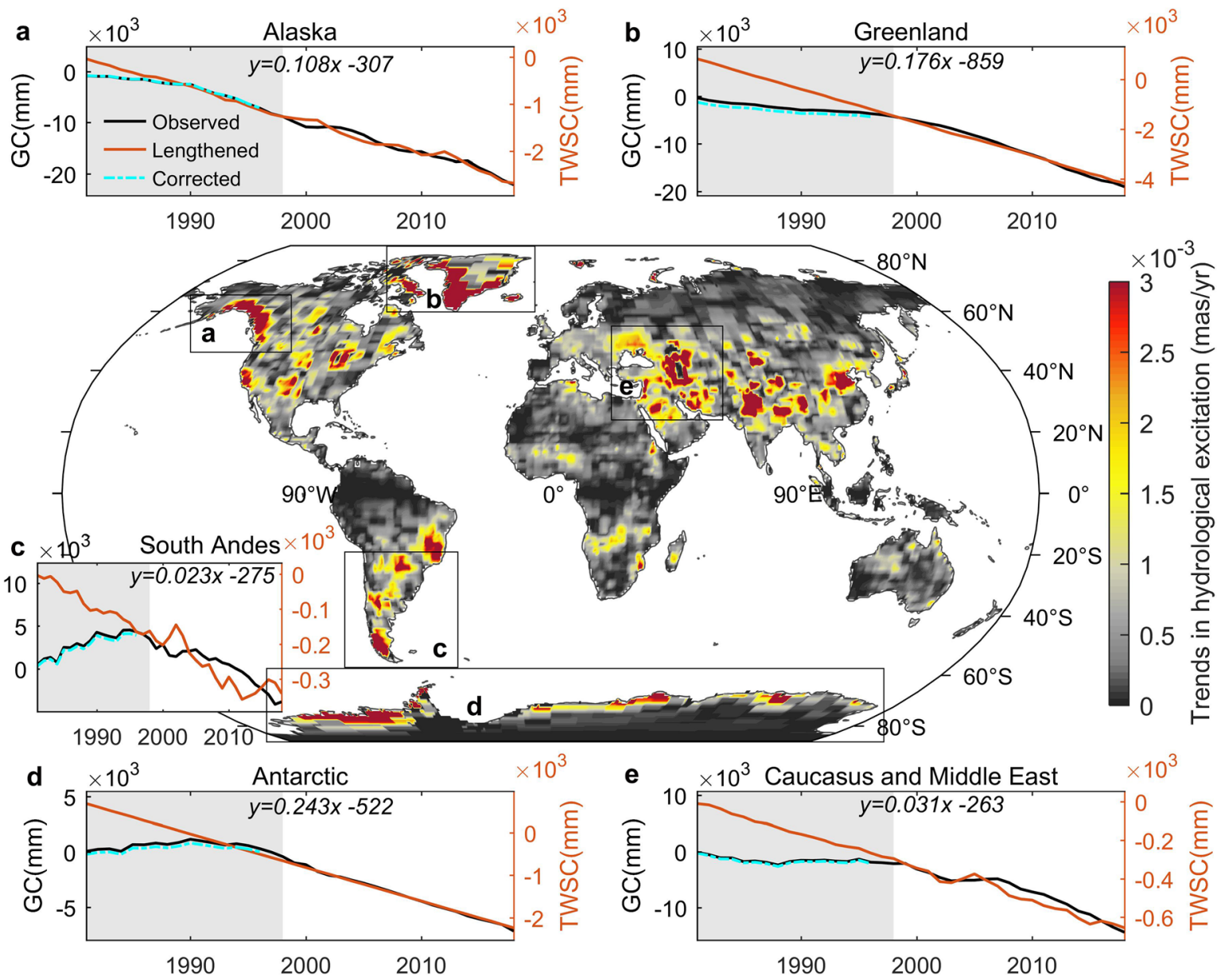

Figure 4. Reconstructions of the TWS over the regions that significantly drove polar drifts during the GRACE/GRACE-FO era. The global distribution map shows the contributions of regional TWS changes to polar drift from April 2004 to June 2020, which are calculated as the square root of the sum of the squares of hydrological excitation trends for two components. The line graphs show the evidence of accelerated glacial melting in the 1990s over the regions that mainly drove polar drifts, that is, (a) Alaska, (b) Greenland, (c) the Southern Andes, (d) Antarctica, (e) the Caucasus, and the Middle East. The black line is the observed GC based on glaciological and geodetic samples from Zemp et al. (2019). The red line is the regional TWS change based on the lengthened GRACE/ GRACE-FO-derived TWS data. The cyan line is the corrected regional TWS change based on the observed glacier change before 1995 using the linear relation between the corrected regional TWS change $(y)$ and observed glacier change ( $x$ ) after 1995 (the equations in the subplots). GC, glacier change; GRACE, Gravity Recovery and Climate Experiment; GRACE-FO, GRACE and its follow-on mission; TWS, terrestrial water storage; TWSC, TWS change.

over all grids that contributed significantly to polar motion (greater than $10^{-3} \mathrm{mas} / \mathrm{yr}$ ) within this region (Figure 4). To correct the lengthened TWS over these regions, the lengthened TWS time series of the grid contributing more than $10^{-3}$ mas/yr to polar motion must be multiplied by the region-specific gain factor from January 1981 to December 1995 (more details in Text S5). After correction, the decreasing tendencies of the grids that contribute significantly to polar motion are slowed or altered (Figure S7). Figure 4 shows that the regional TWS change is in better agreement with the observed glacier change after correction. By converting the corrected TWS into the excitation domain, the excitation of TWS to polar motion over these grids also weakens (Figure S8), and the hydrological excitation fits much better with the residual throughout the entire study period after the correction (Figure 3). The linear trends of the hydrological excitation before the $1990 \mathrm{~s}$ are $0.21 \mathrm{mas} / \mathrm{yr}$ and $0.46 \mathrm{mas} / \mathrm{yr}$ after correction, which are closer to those of the residual $(-0.19$ and -0.12$)$ than the uncorrected trend (2.93 and 1.26) (Figure 3). These experiments support the previous suggestion that accelerated ice melting in glacial areas is the main driver of the observed polar drift after the 1990s. In conclusion, the accelerated TWS decline after the 1990s in Alaska, Greenland, the South Andes, Antarctica, the Caucasus and the Middle East, which decreases by an additional approximately $-48 \mathrm{~mm} / \mathrm{yr}$ compared with that before the $1990 \mathrm{~s}$, mainly drives a rapid polar drift toward $26^{\circ} \mathrm{E}$ at a rate of $3.28 \mathrm{~mm} / \mathrm{yr}$. 


\section{Potential of Polar Motion for Revealing Past Global TWS Change}

Accelerated ice melting in glacial areas cannot explain the entire polar drift in the 1990s, especially for peak-to-peak amplitudes. The unexplainable part might be attributed to the TWS change in nonpolar regions since it contributes the most to periodic variation. According to previous studies, evidence exists for changes in large-scale climatic conditions in approximately 1995. For example, Kwon et al. (2007) showed that a climatic shift in the summer circulation over East Asia increased the amount of precipitation. Shi et al. (2007) and Y. Chen et al. (2009) reported an enhanced water cycle in Northwest China because of rapid global warming, increased precipitation and runoff. Sutton and Dong (2012) found that a substantial shift in the European climate resulted in a wetter northern Europe and a dryer southern Europe. J. Chen et al. (2002) observed that an increase in the strength of the tropical general circulation caused moist conditions in equatorial convective regions and dry conditions in equatorial and subtropical subsidence regions. These climate changes might alter the spatial pattern of the actual TWS change in nonpolar regions. In addition to possible climate change, Figure 4 shows that the areas of groundwater depletion, for example, northern India and the Middle East, also significantly drive polar drift, at least during the GRACE/GRACEFO era. The unsustainable consumption of groundwater for irrigation and other anthropogenic activities has been identified as the likely cause of an observed significant decline in the TWS across northern India during the GRACE era (Rodell et al., 2009). This study investigates groundwater withdrawals to determine the existence of a tipping point in Indian TWS changes in the 1990s. The annual groundwater withdrawals of Indian in 1989, 1990, 2000, and 2010 were 194, 229, 235, 341, and 351 billion cubic meters, respectively (Text S6). It is evident that the annual groundwater withdrawals also rose significantly in 2000, that is, after the 1990s. Moreover, the TWS change in the Caucasus and Middle East cannot be totally explained by the glacier mass change. The TWS change is two orders smaller than the glacier mass change when the covered area of the TWS data is three orders larger than that of the glacier mass data. If spreading the glacier mass change evenly over the covered area of the TWS data, it is still one order smaller than the TWS change. This could be related to the incomplete data collection of glacier mass change in the study of Zemp et al. (2019), but previous studies have also mentioned that the TWS decline in the Middle East has resulted from the human exploitation of groundwater. Zavialov et al. (2003) showed that agricultural diversions and unsustainable use of water resources has led to rapid shallowing of the Aral Sea, which began in the 1960s. Voss et al. (2013) further pointed out that $60 \%$ of the TWS decline in the Middle East from 2003 to 2009 was due to groundwater depletion. Therefore, the TWS change in the 1990s in the Middle East very likely includes groundwater.

However, the TWS in nonpolar regions always changes over space and time. Compared with polar regions that are dominated by nearly linear changes, the TWS change in nonpolar regions, which could even be a wet-dry pattern shift, is more complex and more difficult to reconstruct and correct. Therefore, although this study suggests a change in TWS across nonpolar regions, the actual change in TWS in these regions before the 1990s cannot be deduced given the limited observations and inadequate hydrological models. Nevertheless, this study offers a clue that the residual could be an alternative factor to assess the accuracy of long-term TWS estimates on a global scale. It should also be noted that, for the same TWS change (1 mm/ grid), the regions at low latitudes and high latitudes have a smaller effect on polar motion than those in the mid-latitudes (Figure S9). Thus, polar motion is more sensitive to TWS changes in mid-latitude areas than in other areas.

\section{Conclusions}

A directional change in polar drift occurred in the 1990s. Given the limited information on global TWS changes before the GRACE/GRACE-FO era, even though there is a hypothesis that accelerated ice melting under global warming is the likely cause, the explanation of the physical process is still a challenge. This study aims to illustrate the primary driver of the polar drift change in the 1990s. A comparison of the geodetic excitation and the geophysical excitations from the atmosphere, oceans, and GIA reveals that only the residual has the same change in the linear trends for both components during the 1990s. The residual is mostly attributed to TWS change. A further investigation into the specific TWS change that mainly drove polar drift after the 1990s is then realized by explaining the residual using two sets of modeled TWS changes in different scenarios, that is, the lengthened GRACE/GRACE-FO-derived TWS and the corrected TWS 
associated with observed glacier change. The comparison between the residual and the hydrological excitation based on the lengthened TWS shows that the lengthened TWS only adequately explains the residual after the 1990s. A tipping point in the TWS change is thus observed in the 1990s. By correcting the lengthened TWS with glacier change observations, the deviation between the residual and hydrological excitation before the 1990s has been well addressed, with a trend difference decreasing by $87 \%$ and $58 \%$ for $\chi_{1}$ and $\chi_{2}$. The corrected TWS has a slight impact on polar drift before the 1990s but drives a rapid polar drift toward $26^{\circ} \mathrm{E}$ at a mean rate of $3.26 \mathrm{~mm} / \mathrm{yr}$ after the $1990 \mathrm{~s}$, which is in excellent agreement with that of the residual. The faster ice melting under global warming was the most likely cause of the directional change of the polar drift in the 1990s. The other possible causes are TWS change in non-glacial regions due to climate change and unsustainable consumption of groundwater for irrigation and other anthropogenic activities. The polar drift in 1995 discovered in this study, along with the polar drift in 2005 and 2012 discovered in previous studies, reinforces the suggestion that "TWS is the most plausible causal mechanism for the decadal-like oscillation” (Adhikari \& Ivins, 2016).

\section{Data Availability Statement}

The ERA5-LAND reanalysis data were provided by ECMWF at https://cds.climate.copernicus.eu/cdsapp\#!/ home. The GRACE and GARCE-FO derived TWS data (TELLUS_GRAC-GRFO_MASCON_CRI_GRID_ RL06_V2 version) were provided by JPL at https://podaac.jpl.nasa.gov/dataset/TELLUS_GRAC-GRFO_ MASCON_CRI_GRID_RL06_V2. The observed residual polar motion excitation was provided by IERS at http://hpiers.obspm.fr/eop-pc/index.php?index=excitactive\&lang=en. The water level observations were provided by DAHITI at https://dahiti.dgfi.tum.de/en/map. The Glacier data were provided in the Zenodo repository (https://doi.org/10.5281/zenodo.1492141). The relevant data of annual groundwater withdrawals in Indian were provided by the World Bank at https://databank.worldbank.org/databases.aspx.

Acknowledgments This work was jointly supported by the National Key Research and Development Program of China projects (2018YFE0106500 and 2017YFA0603702), the National Program on Key Basic Research Project of China (2012CB957802), and the Danida Fellowship Centre EOForChina project (18-M01-DTU). The first author is also financially supported by the China Scholarship Council.

\section{References}

Adhikari, S., Caron, L., Steinberger, B., Reager, J. T., Kjeldsen, K. K., Marzeion, B., et al. (2018). What drives 20th century polar motion? Earth and Planetary Science Letters, 502(2018), 126-132. https://doi.org/10.1016/j.epsl.2018.08.059

Adhikari, S., \& Ivins, E. R. (2016). Climate-driven polar motion: 2003-2015. Science Advances, 2(4), e1501693. https://doi.org/10.1126/ sciadv. 1501693

Alkama, R., Decharme, B., Douville, H., Becker, M., Cazenave, A., Sheffield, J., et al. (2010). Global evaluation of the ISBA-TRIP continental hydrological system. Part I: Comparison to GRACE terrestrial water storage estimates and in situ river discharges. Journal of Hydrometeorology, 11(3), 583-600. https://doi.org/10.1175/2010jhm1211.1

Anderle, R. J. (1973). Determination of polar motion from satellite observations. Geophysical Surveys, 1(2), 147-161. https://doi. org/10.1007/BF01449761

Anderle, R. J., \& Beuglass, L. K. (1970). Doppler satellite observations of polar motion. Bulletin Geodesique, 96(1), 125-141. https://doi. org/10.1007/BF02521703

Chen, J., Carlson, B. E., \& Del Genio, A. D. (2002). Evidence for strengthening of the tropical general circulation in the 1990s. Science, 295(5556), 838-841. https://doi.org/10.1126/science.1065835

Chen, J. L., \& Wilson, C. R. (2005). Hydrological excitations of polar motion, 1993-2002. Geophysical Journal International, 160(3), 833839. https://doi.org/10.1111/j.1365-246X.2005.02522.x

Chen, J. L., Wilson, C. R., Ries, J. C., \& Tapley, B. D. (2013). Rapid ice melting drives Earth's pole to the east. Geophysical Research Letters, 40(11), 2625-2630. https://doi.org/10.1002/grl.50552

Chen, J. L., Wilson, C. R., \& Zhou, Y. H. (2012). Seasonal excitation of polar motion. Journal of Geodynamics, 62(8), 8-15. https://doi. org/10.1016/j.jog.2011.12.002

Chen, Y., Xu, C., Hao, X., Li, W., Chen, Y., Zhu, C., \& Ye, Z. (2009). Fifty-year climate change and its effect on annual runoff in the Tarim River Basin, China. Quaternary International, 208(1), 53-61. https://doi.org/10.1016/j.quaint.2008.11.01110.1016/j.quaint.2008.12.014

Gross, R., \& Poutanen, M. (2009). Geodetic observations of glacial isostatic adjustment: Understanding glacial isostatic adjustment: A joint DynaQlim/GGOS Workshop; Espoo, Finland, 23-26 June 2009. Eos, Transactions, American Geophysical Union, 90(41), 365. https:// doi.org/10.1029/2009eo410004

Gross, R. S. (2000). The excitation of the Chandler wobble. Geophysical Research Letters, 27(15), 2329-2332. https://doi. org/10.1029/2000GL011450

Gross, R. S., \& Vondrák, J. (1999). Astrometric and space-geodetic observations of polar wander. Geophysical Research Letters, 26(14), 2085-2088. https://doi.org/10.1029/1999GL900422

Hirschi, M., \& Seneviratne, S. I. (2017). Basin-scale water-balance dataset (BSWB): An update. Earth System Science Data, 9(1), 251-258. https://doi.org/10.5194/essd-9-251-2017

Hirschi, M., Seneviratne, S. I., Hagemann, S., \& Schär, C. (2007). Analysis of seasonal terrestrial water storage variations in regional climate simulations over Europe. Journal of Geophysical Research, 112, D22109. https://doi.org/10.1029/2006jd008338

Hirschi, M., Seneviratne, S. I., \& Schär, C. (2006). Seasonal variations in terrestrial water storage for major midlatitude river basins. Journal of Hydrometeorology, 7(1), 39-60. https://doi.org/10.1175/Jhm480.1

Hirschi, M., Viterbo, P., \& Seneviratne, S. I. (2006). Basin-scale water-balance estimates of terrestrial water storage variations from ECMWF operational forecast analysis. Geophysical Research Letters, 33(21), L21401. https://doi.org/10.1029/2006gl027659 
Höpfner, J. (2004). Low-frequency variations, chandler and annual wobbles of polar motion as observed over one century. Surveys in Geophysics, 25(1), 1-54. https://doi.org/10.1023/B:Geop.0000015345.88410.36

Kumar, S. V., Zaitchik, B. F., Peters-Lidard, C. D., Rodell, M., Reichle, R., Li, B., et al. (2016). Assimilation of gridded GRACE terrestrial water storage estimates in the North American land data assimilation system. Journal of Hydrometeorology, 17(7), 1951-1972. https:// doi.org/10.1175/Jhm-D-15-0157.1

Kwon, M., Jhun, J.-G., \& Ha, K.-J. (2007). Decadal change in east Asian summer monsoon circulation in the mid-1990s. Geophysical Research Letters, 34(21), L21706. https://doi.org/10.1029/2007GL031977

Liu, S., Deng, S., Mo, X., \& Yan, H. (2018). Indexing the relationship between polar motion and water mass change in a giant river basin. Science China Earth Sciences, 61(8), 1065-1077. https://doi.org/10.1007/s11430-016-9211-2

Long, D., Pan, Y., Zhou, J., Chen, Y., Hou, X., Hong, Y., et al. (2017). Global analysis of spatiotemporal variability in merged total water storage changes using multiple GRACE products and global hydrological models. Remote Sensing of Environment, 192, 198-216. https:// doi.org/10.1016/j.rse.2017.02.011

McCarthy, D. D., \& Luzum, B. J. (1996). Path of the mean rotational pole from 1899 to 1994. Geophysical Journal International, 125(2), 623-629. https://doi.org/10.1111/j.1365-246X.1996.tb00024.X

Mueller, B., Hirschi, M., \& Seneviratne, S. I. (2011). New diagnostic estimates of variations in terrestrial water storage based on ERA-Interim data. Hydrological Processes, 25(7), 996-1008. https://doi.org/10.1002/hyp.7652

Nakada, M., Okuno, J. i., Lambeck, K., \& Purcell, A. (2015). Viscosity structure of Earth's mantle inferred from rotational variations due to GIA process and recent melting events. Geophysical Journal International, 202(2), 976-992. https://doi.org/10.1093/gji/ggv198

Rodell, M., Velicogna, I., \& Famiglietti, J. S. (2009). Satellite-based estimates of groundwater depletion in India. Nature, 460(7258), 9991002. https://doi.org/10.1038/nature08238

Roy, K., \& Peltier, W. R. (2011). GRACE era secular trends in Earth rotation parameters: A global scale impact of the global warming process? Geophysical Research Letters, 38, L10306. https://doi.org/10.1029/2011gl047282

Scanlon, B. R., Zhang, Z., Save, H., Sun, A. Y., Müller Schmied, H., van Beek, L. P. H., et al. (2018). Global models underestimate large decadal declining and rising water storage trends relative to GRACE satellite data. Proceedings of the National Academy of Sciences of the United States of America, 115(6), E1080-E1089. https://doi.org/10.1073/pnas.1704665115

Seneviratne, S. I., Viterbo, P., Lüthi, D., \& Schär, C. (2004). Inferring changes in terrestrial water storage using ERA-40 reanalysis data: The Mississippi River basin. Journal of Climate, 17(11), 2039-2057. https://doi.org/10.1175/1520-0442(2004)017<2039:Icitws>2.0.Co;2

Shi, Y., Shen, Y., Kang, E., Li, D., Ding, Y., Zhang, G., \& Hu, R. (2007). Recent and future climate change in Northwest China. Climatic Change, 80(3-4), 379-393. https://doi.org/10.1007/s10584-006-9121-7

Sutton, R. T., \& Dong, B. (2012). Atlantic Ocean influence on a shift in European climate in the 1990s. Nature Geoscience, 5(11), 788-792. https://doi.org/10.1038/ngeo1595

Tang, Q., Gao, H., Yeh, P., Oki, T., Su, F., \& Lettenmaier, D. P. (2010). Dynamics of terrestrial water storage change from satellite and surface observations and modeling. Journal of Hydrometeorology, 11(1), 156-170. https://doi.org/10.1175/2009jhm1152.1

Tapley, B. D., Bettadpur, S., Watkins, M., \& Reigber, C. (2004). The gravity recovery and climate experiment: Mission overview and early results. Geophysical Research Letters, 31(9). https://doi.org/10.1029/2004GL019920

Thomas, R., Frederick, E., Krabill, W., Manizade, S., \& Martin, C. (2006). Progressive increase in ice loss from Greenland. Geophysical Research Letters, 33(10), L10503. https://doi.org/10.1029/2006gl026075

Verbesselt, J., Hyndman, R., Newnham, G., \& Culvenor, D. (2010). Detecting trend and seasonal changes in satellite image time series. Remote Sensing of Environment, 114(1), 106-115. https://doi.org/10.1016/j.rse.2009.08.014

Voss, K. A., Famiglietti, J. S., Lo, M., De Linage, C., Rodell, M., \& Swenson, S. C. (2013). Groundwater depletion in the Middle East from GRACE with implications for transboundary water management in the Tigris-Euphrates-Western Iran region. Water Resources Research, 49(2), 904-914. https://doi.org/10.1002/wrcr.20078

Watkins, M. M., Wiese, D. N., Yuan, D.-N., Boening, C., \& Landerer, F. W. (2015). Improved methods for observing Earth's time variable mass distribution with GRACE using spherical cap mascons. Journal of Geophysical Research: Solid Earth, 120(4), 2648-2671. https:// doi.org/10.1002/2014jb011547

Watts, L. M., \& Laffan, S. W. (2014). Effectiveness of the BFAST algorithm for detecting vegetation response patterns in a semi-arid region. Remote Sensing of Environment, 154, 234-245. https://doi.org/10.1016/j.rse.2014.08.023

Yu, Y., Lin, Z.-H., \& Qin, Z.-K. (2018). Improved EOF-based bias correction method for seasonal forecasts and its application in IAP AGCM4.1. Atmospheric and Oceanic Science Letters, 11(6), 499-508. https://doi.org/10.1080/16742834.2018.1529532

Zavialov, P. O., Kostianoy, A. G., Emelianov, S. V., Ni, A. A., Ishniyazov, D., Khan, V. M., \& Kudyshkin, T. V. (2003). Hydrographic survey in the dying Aral Sea. Geophysical Research Letters, 30(13), 1659. https://doi.org/10.1029/2003GL017427

Zemp, M., Huss, M., Thibert, E., Eckert, N., McNabb, R., Huber, J., et al. (2019). Global glacier mass changes and their contributions to sea-level rise from 1961 to 2016. Nature, 568(7752), 382-386. https://doi.org/10.1038/s41586-019-1071-0

\section{References From the Supporting Information}

Deng, S., Liu, S., \& Mo, X. (2020). Assessment of three common methods for estimating terrestrial water storage change with three reanalysis datasets. Journal of Climate, 33(2), 511-525. https://doi.org/10.1175/jcli-d-18-0637.1

Liu, S., Deng, S., Mo, X., Yan, H., Wang, Y., Shao, Y., \& Peng, G. (2017). Preliminary study on the correspondence of turning points between global flood occurrences and polar motion. In G. Syme, D. Hatton MacDonald, B. Fulton, \& J. Piantadosi (Eds.), MODSIM2017, 22nd International Congress on Modelling and Simulation (pp. 1731-1737). Modelling and Simulation Society of Australia and New Zealand. Retrieved from http://www.mssanz.org.au/modsim2017/L14/liu.pdf

Wahr, J., Nerem, R. S., \& Bettadpur, S. V. (2015). The pole tide and its effect on GRACE time-variable gravity measurements: Implications for estimates of surface mass variations. Journal of Geophysical Research: Solid Earth, 120(6), 4597-4615. https://doi. org/10.1002/2015JB011986C 